\title{
Safety of apixaban for venous thromboembolism prophylaxis: the evidence to date
}

\author{
This article was published in the following Dove Press journal: \\ Drug, Healthcare and Patient Safety \\ 18 February 2016 \\ Number of times this article has been viewed
}

\author{
Vladimir Trkulja \\ Department of Pharmacology, Zagreb \\ University School of Medicine, Zagreb, \\ Croatia
}

\begin{abstract}
Apixaban, a direct orally active anticoagulant (selective, direct factor Xa inhibitor) is approved for (primary) prevention of venous thromboembolism (VTE) in patients undergoing elective total-hip or total-knee arthroplasty, for acute treatment/prevention of recurrent events in patients with VTE, and extended prophylaxis in patients with a history of VTE. Another approved use is prevention of stroke and systemic embolism in patients with nonvalvular atrial fibrillation. The present overview focuses on the safety of apixaban specifically in the VTE setting. Apixaban displays favorable pharmacokinetic properties: simple twice-daily dosing, low inter- and intrasubject variability, dose and time linearity, and multiple elimination pathways not critically dependent on either renal or metabolic mechanisms. An extensive nonclinical program and the overall clinical development program (all approved and tested indications) provided no signal that would indicate any particular specific safety concern related to apixaban apart from the increased risk of bleeding. With regard to the approved VTE indications, safety (and efficacy) was assessed in five large pivotal Phase III trials. In comparison to currently recommended standard treatments, apixaban shows superior efficacy, while at the same time no excess risk of bleeding in patients undergoing total-hip or total-knee arthroplasty. In treatment of VTE, apixaban shows noninferior efficacy and a reduced risk of bleeding, whereas in extended prophylaxis it reduced the risk of VTE/VTE-related deaths, with no increased risk of relevant bleedings in comparison to placebo. Documented clinical experience with apixaban in daily practice is currently sparse. However, its use is progressively increasing, and there has been no signal so far that would materially change the perception of its safety profile as defined in the premarketing trials.
\end{abstract}

Keywords: apixaban, venous thromboembolism, treatment, prophylaxis, safety

\section{Introduction}

Apixaban, chemically 1-(4-methoxyphenyl)-7-oxo-6-[4-(2-oxopiperidin-1-yl) phenyl]-4,5,6,7-tetrahydro-1 $\mathrm{H}$-pyrazolo[3,4-c]pyridine-3-carboxamide $\left(\mathrm{C}_{25} \mathrm{H}_{25} \mathrm{~N}_{5} \mathrm{O}_{4}\right.$, molecular weight [MW] 459.5), is an orally active direct inhibitor of the activated coagulation factor X (fXa). ${ }^{1}$ It falls into a relatively recently established therapeutic class of direct orally active anticoagulants (DOACs) together with the direct thrombin inhibitor dabigatran and two other approved direct fXa inhibitors: rivaroxaban and edoxaban. Apixaban is formulated as immediate-release film-coated tablets containing $2.5 \mathrm{mg}$ or $5.0 \mathrm{mg}$ of the active substance that are dosed twice daily (bis in die [BID]).,3 Apixaban is currently approved for: 1) prevention of venous thromboembolic (VTE) events in patients undergoing total-hip arthroplasty (THA) or total-knee arthroplasty (TKA) (primary prevention); 2) treatment of acute deep vein thrombosis (DVT) and/or
Correspondence: Vladimir Trkulja Department of Pharmacology, Zagreb University School of Medicine, 3 Šalata Ulica, Zagreb 10000 , Croatia

Tel +385 I 4566830

Fax +385 I 20049200

Email vtrkulja@mef.hr
Drug, Healthcare and Patient Safety 2016:8 25-38

(c) (1) (\$) ๑ 2016 Trkula. This work is published and licensed by Dove Medical Press Limited. The full terms of this license are available at https://www.dovepress.com/terms.php cc. hereby accept the Terms. Non-commercial uses of the work are permitted without any further permisision from Dove Medical Press Limited, provided the work is properly atrtibuted. For permision for commercial use of this work, please see paragraphs 4.2 and 5 of our Terms (htpps://www.dovepress. com/terms.php).
Dovepress

http://dx.doi.org/10.2147/DHPS.S744I0

25 
pulmonary embolism (PE), ie, venous thromboembolism (VTE) and prevention of recurrent events (secondary prevention); and 3) prevention of arterial thromboembolic incidents, ie, stroke and systemic embolism in patients with nonvalvular atrial fibrillation (NVAF) requiring anticoagulation. In these indications, apixaban has been evaluated in comparison to the standard-of-care treatments, ie, enoxaparin, warfarin, or fondaparinux, ${ }^{4,5}$ to placebo for extended VTE prevention in patients who had completed a 6- to 12-month anticoagulant treatment after the index event without recurrence and were at equipoise regarding continuation of anticoagulation, ${ }^{5}$ and to warfarin or aspirin (if warfarin was unsuitable) in patients with NVAF. ${ }^{6}$ All approved indications refer to adult patients, since apixaban has not been evaluated in children and adolescents $<18$ years of age. Apixaban has not been evaluated in pregnant or breast-feeding women either. ${ }^{2,3}$

During the regulatory clinical development, apixaban was assessed in some other settings as well. One Phase II randomized, double-blind, placebo-controlled, dose-ranging trial has been completed, indicating therapeutic potential of apixaban in primary prevention of VTE in ambulatory patients with cancer receiving chemotherapy. ${ }^{7}$ One large Phase III randomized double-blind trial of apixaban $2.5 \mathrm{mg}$ BID over 30 days vs enoxaparin $40 \mathrm{mg}$ once daily over 6-14 days for prevention of VTE in acutely medically ill patients with at least one additional risk factor for VTE provided no evidence of VTE-prevention benefit, while there was increased risk of major bleeding. ${ }^{8}$ Apixaban was also evaluated for prevention of recurrent ischemic events in patients with acute coronary syndrome over the subsequent 6 months. One Phase II randomized, double-blind, placebo-controlled, dose-ranging trial (apixaban $5-20 \mathrm{mg}$ /day on top of antiplatelets) demonstrated too high a risk of major or nonmajor clinically relevant bleeding with $20 \mathrm{mg}$ /day. Lower doses (5 or $10 \mathrm{mg} /$ day) also showed a higher risk of bleeding, but indicated a trend toward reduced recurrent ischemic events. ${ }^{9}$ However, a subsequent large Phase III randomized placebocontrolled trial of apixaban $5 \mathrm{mg}$ BID in this indication was stopped prematurely, due to a lack of a beneficial effect and an increased risk of major bleeding. ${ }^{10} \mathrm{~A}$ simultaneous placebocontrolled Phase II trial in this indication in Japanese patients (apixaban $2.5 \mathrm{mg}$ BID or $5 \mathrm{mg}$ BID) was consequently also terminated prematurely. The accumulated data indicated a higher risk of major bleeding with both doses. ${ }^{11}$

The present overview addresses the safety of apixaban, specifically in the prevention of VTE. The focus is on the approved indications, ie, THA/TKA and acute and extended treatment in VTE patients. Data from other settings, ie, primary VTE prevention in cancer patients and medically ill patients, are in this context considered supportive: the mechanism of action and expected benefit are the same; however, the underlying conditions/comorbidity may affect the safety aspects of apixaban.

VTE subsumes two related entities: DVT, ie, thrombosis of the deep veins of the lower extremities, and PE. Most patients with PE suffer also from DVT (not necessarily symptomatic) and vice versa. ${ }^{11,12}$ As pointed out by the practice guidelines on VTE by the American College of Chest Physicians, ${ }^{13}$ in the strict sense VTE refers specifically to DVT/PE. Other venous thrombotic events, eg, acute upper-extremity DVT or thrombosis of the splanchnic veins or the hepatic vein, are not embraced by this term. It should be noted that apixaban has been formally evaluated and approved specifically for primary prevention (THA, TKA) and treatment/secondary prevention of VTE in the context of DVT/PE. The risk-benefit relationship for apixaban in other conditions characterized by DVT and potential embolism has not been formally assessed as yet.

\section{Summary of pharmacological properties of apixaban}

Apixaban is a highly potent reversible inhibitor of activated human fXa. It binds to the enzymatically active site of fXa and inhibits free fXa, fXa in the prothrombinase complex and thrombin-associated fXa. Selectivity of apixaban for fXa is illustrated by its greatly lower potency in inhibition of a range of other human enzymes of the coagulationanticoagulation system. ${ }^{1,14,15}$ Table 1 outlines the pharmacodynamic profile of apixaban as established in in vitro assays during its discovery and development. One independent study demonstrated an inhibitory effect of apixaban on platelet and fibrin interactions with damaged endothelium in the rabbit aorta perfusion model. ${ }^{16}$ Overall, in vitro data indicate that in addition to direct antithrombotic/anticoagulant activity, apixaban also potently indirectly inhibits platelet aggregation.

The pharmacokinetics (PK) and in vivo pharmacodynamics (PD) of apixaban have been evaluated in extensive nonclinical programs and in around 40 human studies. Additionally, Phase II and III trial data were used for population PK and PK-PD modeling. Data are available from regulatory assessment reports ${ }^{4-6,17,18}$ and published studies. ${ }^{19-43}$ Table 2 summarizes the main features of apixaban. From the safety standpoint, the fact that apixaban is highly plasma proteinbound and hence nondialyzable might be an impractical property in the case of excess anticoagulant effect. Generally, 
Table I Outline of the pharmacodynamic profile of apixaban as established in in vitro assays during discovery and preclinical development

\begin{tabular}{|c|c|}
\hline \multicolumn{2}{|l|}{ Enzyme inhibition, $K_{i}(n M)$} \\
\hline $\mathrm{fXa}$ & $0.08 \mathrm{I}$ \\
\hline Activated protein $\mathrm{C}$ & $>30$ \\
\hline Chymotrypsin & 3.5 \\
\hline $\mathrm{flXa}$ & $>15$ \\
\hline fVlla & $>15$ \\
\hline Plasma kallikrein & 3.7 \\
\hline Plasmin & $>25$ \\
\hline Thrombin & 3.1 \\
\hline Tissue plasminogen activator & $>40$ \\
\hline Trypsin & $>20$ \\
\hline \multicolumn{2}{|c|}{ Coagulation tests, concentration inducing doubling of time $(\mu \mathrm{M})$} \\
\hline Prothrombin time & 3.6 \\
\hline Modified prothrombin time & 0.37 \\
\hline Activated partial thromboplastin time & 7.4 \\
\hline HepTest* & 0.4 \\
\hline \multicolumn{2}{|c|}{ Platelet aggregation in platelet-rich plasma, inhibition } \\
\hline $\begin{array}{l}\text { ADP-, collagen-, } \gamma \text {-thrombin-, } \\
\alpha \text {-thrombin-, or TRAP-induced }\end{array}$ & $\begin{array}{l}\text { No direct effect at } 1,3 \text {, or } \\
10 \mu \mathrm{M}\end{array}$ \\
\hline $\begin{array}{l}\text { Tf-mediated coagulation pathway- } \\
\text { derived thrombin-induced }\end{array}$ & Inhibition (indirect) $\mathrm{IC}_{50}=4 \mathrm{nM}$ \\
\hline \multicolumn{2}{|c|}{ Thrombin generation (thrombogram), inhibition } \\
\hline $\begin{array}{l}\text { Tf-initiated thrombin generation in } \\
\text { platelet-poor plasma }\end{array}$ & $\begin{array}{l}\text { Inhibition (rate) } I C_{50}=50 \mathrm{nM} \\
\text { Inhibition (thrombin peak) } I C_{50} \\
=100 \mathrm{nM}\end{array}$ \\
\hline $\begin{array}{l}\text { Tf-induced thrombin generation in } \\
\text { platelet-rich plasma }\end{array}$ & Inhibition $\mathrm{IC}_{50}=37 \mathrm{nM}$ \\
\hline
\end{tabular}

Notes: *Assay system for quantification of heparin based on heparin-mediated $\mathrm{f} X a$ inhibition resulting in prolonged clotting time. Data from Wong et al,' Wong et al, ${ }^{14}$ and Jian et al. ${ }^{15}$

Abbreviations: $\mathrm{f} X \mathrm{a}$, factor $\mathrm{Xa}$; Tf, tissue factor; TRAP, thrombin receptor-activating peptide; $I \mathrm{C}_{50}$, half-maximal inhibitory concentration.

however, apixaban displays favorable, predictable PK properties similar in healthy subjects and in patients with approved indications: low inter- and intrasubject variability, modest peak-trough fluctuation, no food interaction, possibility of reduction of total exposure with activated charcoal administered 2-6 hours since dosing, multiple elimination mechanisms not critically depending on either metabolism or renal function, no effect on key metabolizing enzymes or transport proteins, indicating low potential for relevant PK drug-drug interactions, and an elimination half-life that allows for a relatively rapid loss of anticoagulant effect. Dedicated studies and population PK models have demonstrated negligible differences in peak and total exposure or apparent total body clearance between men and women, mild differences between elderly and younger subjects, mild effect of body weight, and no effect of race.

In line with its mechanism of action, apixaban increases anti-fXa activity in a dose/concentration-dependent manner (a strong exposure-effect linear relationship), but also other routine indicators of the coagulation system (modified prothrombin time, prothrombin time, international normalized ratio [INR], and activated partial thromboplastin time), although with considerably more variability in the exposure-effect relationship rendering these indicators inappropriate for estimation of apixaban plasma concentration/anticoagulant activity. While dose-dependent efficacy of apixaban was demonstrated in dose-ranging trials in some but not all VTE settings (Table 3), the risk of relevant bleeding increases with higher exposure, although the response curve is flat (Table 2).

Based on dedicated studies and PK-PD modeling, only a few dosing restrictions/dose adjustments are required from the safety standpoint in indications related to VTE: 1) no dosing adjustment is required based on age, sex, body weight, or in patients with creatinine clearance $(\mathrm{CrCl}) \geq 30$ $\mathrm{mL} / \mathrm{min}$; in patients with $\mathrm{CrCl} 15-29 \mathrm{~mL} / \mathrm{min}$, apixaban is to be used with caution; it should not be used in patients with $\mathrm{CrCl}<15 \mathrm{~mL} / \mathrm{min}$ or those on dialysis, due to a lack of clinical experience; 2) no dose adjustment is needed in patients with mild-to-moderate hepatic impairment, it is not recommended in those with severe impairment, and it is contraindicated in patients with hepatic failure associated with coagulopathy and clinically relevant bleeding risk; since patients with transaminases $>2 \times$ or total bilirubin $>1.5 \times$ the upper limit of normal were not included in clinical trials, caution is needed in this population; 3 ) drugs not recommended for concomitant use with apixaban are strong CYP3A4/P-gp inhibitors ("dual inhibitors"), eg, azole antifungals and HIV protease inhibitors like ritonavir, while it may be used concomitantly with "nonstrong" inhibitors (eg, diltiazem, naproxen, verapamil, amiodarone, quinidine) without dose adjustments; 4) apixaban may be used without dose adjustments concomitantly with strong CYP3A4 and/or P-gp inducers like rifampin, carbamazepine, barbiturates of Saint John's wort, but its use is not recommended, due to potentially reduced efficacy; 5) concomitant use of apixaban and other anticoagulants is contraindicated, due to an increased risk of bleeding; and 6) use of apixaban in patients requiring mono- or dual-antiplatelet therapy requires a careful consideration of risks and benefits. Although formal interaction studies showed no additional effect on platelet aggregation or on clotting tests when apixaban was combined with lowdose aspirin, clopidogrel, or prasugrel, or a combination of clopidogrel + aspirin or prasugrel + aspirin (Table 2), an increased risk of major bleeding with combined treatment vs apixaban alone was observed in clinical trials in patients with NVAF or acute coronary syndromes. ${ }^{2,3}$ 
Table 2 Outline of the main clinical pharmacokinetic and pharmacodynamic properties of oral apixaban characterized in premarketing development

\section{Pharmacokinetics \\ Absorption, BA, food effect}

Distribution

Biotransformation

Effect on enzymes/transporters Elimination

Dose and time dependence

Inter- and intrasubject variability Effect of demographics/morbidity

Effect of renal failure

Effect of hepatic failure Drug-drug interactions

\section{Pharmacodynamics}

Measures of anticoagulant activity and exposure-activity relationship

Exposure-major bleeding relationship

Effect of demographics/morbidity on anticoagulant activity

Anticoagulation in renal failure Anticoagulation in hepatic failure Drug-drug interactions and effect on anticoagulation
Rapidly absorbed in small intestine; enterohepatic and enteroenteric recirculation; "late" $\mathrm{T}_{\max }(\sim 3 \mathrm{hrs})$ and $\sim 50 \%$ absolute BA likely, because substrate to efflux proteins P-gP and BCRA; no food effect Plasma protein binding $\sim 90 \%$ (albumin), no accumulation in erythrocytes; $V_{D} \sim 21 \mathrm{~L}$

$\sim 32 \%$ of dose metabolized; no active metabolites; O-demethylation, hydroxylation, and sulfation of hydroxyO-methyl apixaban; CYP3A4/5 main, IA2, 2J2, 2C8, 2C9, 2CI9, IA3, IEI minor; SULTIAI, IA2

No effect on CYP3A4/5, 2B6, IA2, P-gP activity; not a substrate of and no effect on OATPIBI/3 or OATI/3 $\sim 27 \%$ unchanged via kidneys (metabolites in urine minor), rest by feces ( $60 \%$ unchanged apixaban, mainly by intestinal secretion, minor via bile; metabolites the same); $\mathrm{CL}_{\mathrm{T} / \mathrm{F}} \sim 5 \mathrm{~L} / \mathrm{h} ; t_{1 / 2} \sim 13$ hours

Dose-proportional (5-50 mg single dose); steady state after 3 days of BID dosing; with BID (2.5-25 mg) dosing peak:trough ratio $\sim 3$; nearly time-proportional, with accumulation index $\sim 1.7$ across doses Intrasubject variability for peak and total exposure $\sim 20 \%$, intersubject $30 \%-40 \%$

No effect of sex or race; age $\geq 65$ yrs vs $18-40$ yrs $\sim 30 \%$ and $20 \% \uparrow$ peak and total exposure; body weight $\leq 50 \mathrm{~kg}$ or $\geq 120 \mathrm{~kg}$ vs $65-85 \mathrm{~kg} \sim 20 \% \uparrow$ or $\downarrow$ total exposure, respectively; pop-PK model $\mathrm{CL}_{\mathrm{T} / \mathrm{F}} \downarrow 10 \%$ or $\uparrow \mathrm{I} \%$ at 80 or 40 vs 60 years, respectively; $\downarrow 24 \%$ early post-TKA/THA, $\downarrow 18 \%$ if AF patient vs healthy Mild $(\mathrm{CrCl}>50 \mathrm{~mL} / \mathrm{min})$, moderate $(\mathrm{CrCl} 30-50 \mathrm{~mL} / \mathrm{min})$, or severe $(\mathrm{CrCl} \mathrm{I5-29} \mathrm{mL/min)} \mathrm{no} \mathrm{effect} \mathrm{on} \mathrm{peak}$ exposure or $t_{1 / 2}$, total exposure $\uparrow$ to $40 \%$ and $\mathrm{CL}_{\mathrm{T} / \mathrm{F}}$ gradually decreases; renal clearance $\downarrow 50 \%-60 \%$; Pop-PK $\mathrm{CL}_{\mathrm{T} / \mathrm{F}} \downarrow 15 \%$ in mild, $25 \%$ in moderate, and $44 \%$ in severe failure $(\mathrm{CrCl}<15 \mathrm{~mL} / \mathrm{min}$ or dialyzed - unknown) Mild to moderate (Child-Pugh A or B) no effect; severe failure - unknown

Drug effects on apixaban: activated charcoal $2-6$ hours postdose no effect on peak, total exposure $\downarrow 28 \%-50 \%$, $t_{1 / 2} \downarrow 50 \%$ (inhibited enteroenteric recirculation); atenolol, clopidogrel, prasugrel, enoxaparin, famotidine - no effect; strong CYP3A/Pg-p inhibitor ketoconazole peak and total exposure $\uparrow 60 \%$ and $100 \%$, respectively; moderate CYP3A4 inhibitor diltiazem peak and total exposure $\uparrow 40 \%$; P-gp inhibitor naproxen peak and total exposure $\uparrow 55 \%-60 \%$; strong CYP3A4 and P-gP inducer rifampin $\downarrow 50 \%$ peak and total exposure

Apixaban: no effect on digoxin, clopidogrel, prasugrel, naproxen, aspirin, salicylic acid, atenolol, or enoxaparin

Apixaban increases anti-factor Xa activity, mPT, PT, INR, and aPTT; strong linear relationship between pointplasma concentrations, peak or total exposure, and anti-factor Xa activity (by chromogenic assays); effecttime profile follows the concentration-time profile; considerably more variability in the exposure - $\mathrm{mPT}$, PT, and particularly INR and aPTT relationship; effects on anti-Xa, mPT, PT, INR, and aPTT with rapid onset, full anticoagulant activity after $\sim 6$ days of BID dosing PK-PD model: increase in steady-state total exposure over dosing interval $\left(A \cup C_{t}\right)$ increases the odds of major bleeding (OR I.I I 8 by I $\mu \mathrm{g} \cdot \mathrm{h} / \mathrm{mL}$ increase), but exposure-response curve flat; threefold increase in probability (from $\sim 1.3 \%$ to $\sim 3.9 \%$ ) across a $2 \mathrm{l}$-fold increase $\left(0.5-10.5 \mu \mathrm{g} \cdot \mathrm{h} / \mathrm{mL}\right.$ ) in $A U C_{t} ; A U C_{t}$ in healthy subjects with $10 \mathrm{mg}$ BID $=2.0 \mu \mathrm{g} \cdot \mathrm{h} / \mathrm{mL}$

Sex and age do not change the exposure to anti-Xa, mPT, PT, or INR relationship; peak and integrated (AUC) anti-Xa effect over time in elderly vs young or men vs women within $\pm 15 \%, \mathrm{mPT}$ and INR within $15 \%-20 \%$ (the same holds in different races); body-weight effects on anti-Xa in agreement with the effect on total exposure (the same holds for the treated condition [THA/TKA, VTE, NVAF])

Anti-Xa activity and INR increase in line with modestly increased exposure, with declining renal function Child-Pugh A or B: no difference in peak or integrated anti-Xa or INR vs healthy subjects

PK-PD model indicates a relatively $70 \%$ increased risk of major bleeding when apixaban coadministered with ketoconazole; no major increase in risk with diltiazem or naproxen; additive anti-Xa activity with enoxaparin; reduced efficacy anticipated with rifampin; coadministration with aspirin, clopidogrel, prasugrel, or combination (aspirin + clopidogrel) - no additional effect on platelet aggregation, anti-Xa, mPT, or INR In a dedicated study, apixaban 10 or 50 mg once daily over 3 days did not prolong QTc oral administration; $\mathrm{CrCl}$, creatinine clearance; INR, international normalized ratio; mPT, modified prothrombin time; NVAF, nonvalvular atrial fibrillation; OR, odds ratio; PK-PD, pharmacokinetic-pharmacodynamic; Pop-PK, population pharmacokinetic modeling; QTc, QT interval corrected for heart rate (Fridericia method); THA, total-hip arthroplasty; TKA, total-knee arthroplasty; $t_{1 / 2}$, elimination half-life; $\mathrm{T}_{\max }$, time to peak concentration; $\mathrm{V}_{\mathrm{D}}$, apparent volume of distribution; $\mathrm{VTE}$, venous thromboembolism.

\section{Summary of clinical efficacy in prevention/treatment of VTE}

Anticoagulants are specific in that their clinical utility depends equally on two facets of their biological activity: prevention of thromboembolic effects and the risk of bleeding.
Therefore, consideration of the safety of apixaban requires that its efficacy is at least briefly addressed. Table 3 summarizes the main particulars and efficacy outcomes in Phase II and Phase III trials of apixaban for prevention/treatment of VTE in the approved and tested indications. In patients 


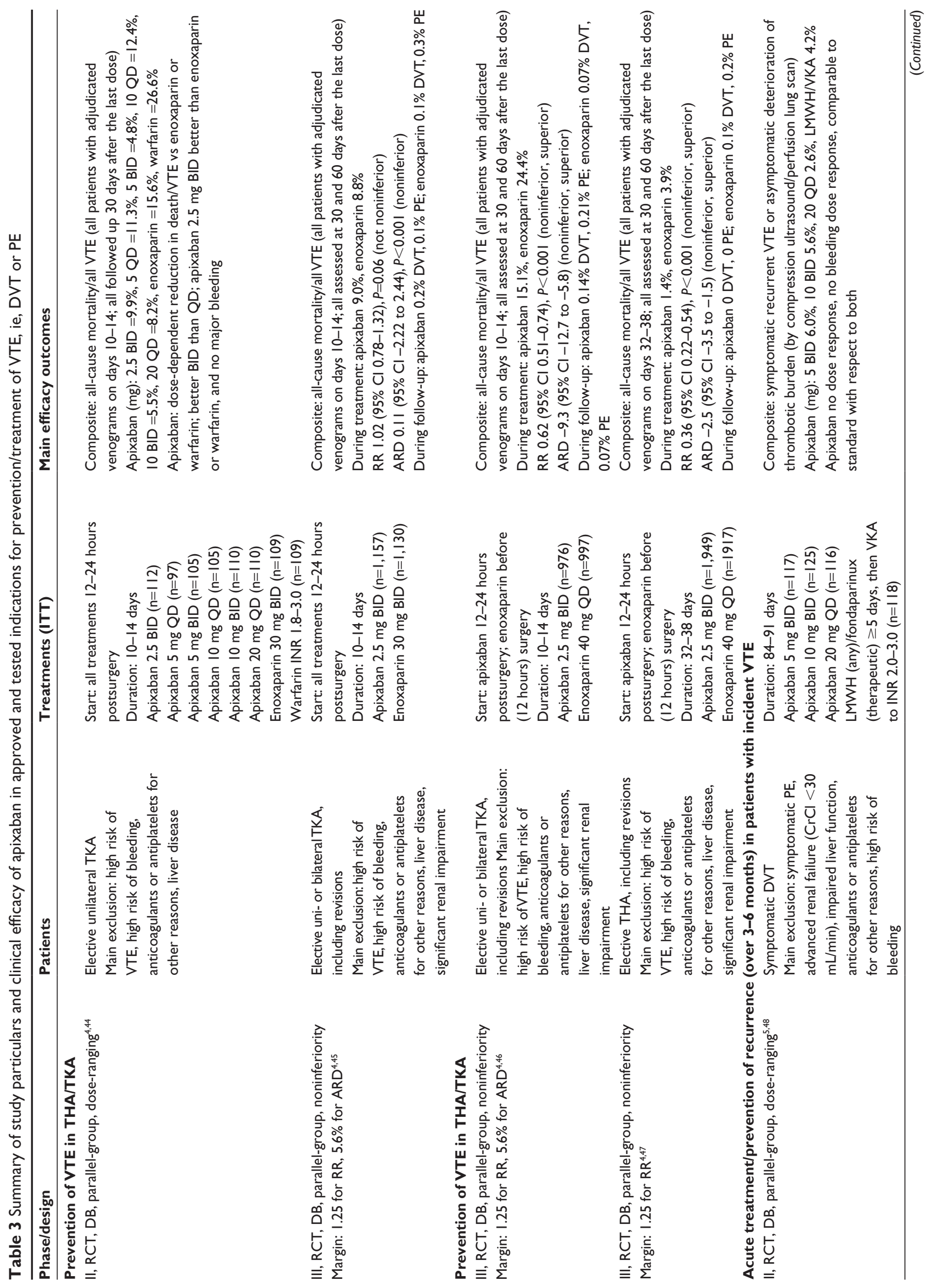




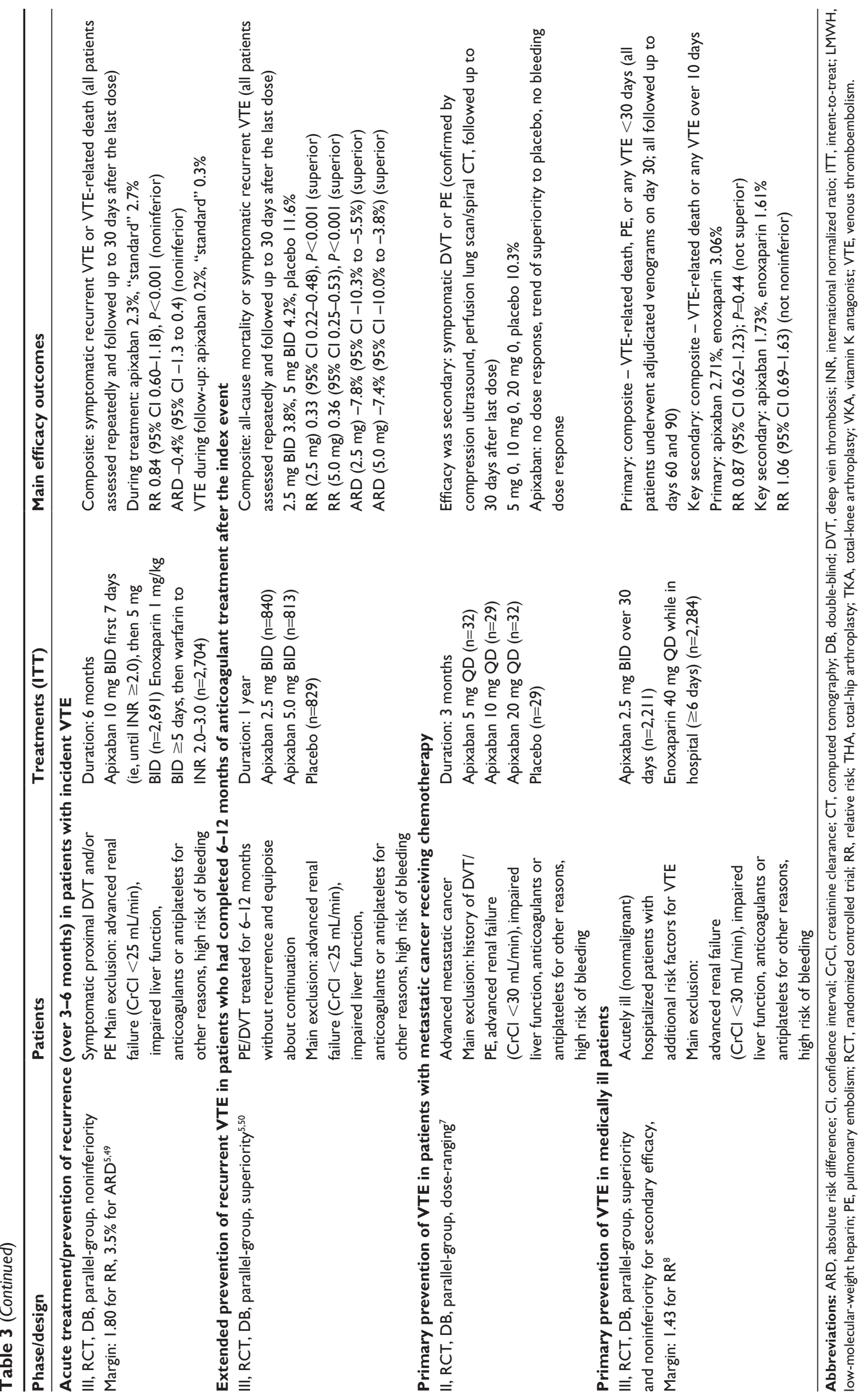


undergoing THA or TKA, apixaban is both noninferior and superior in prevention of all-cause mortality and all VTE vs the "European-style enoxaparin" treatment (40 mg once daily [quaque die $\{\mathrm{QD}\}$ ] subcutaneously), whereas a comparison with the "American-style enoxaparin" (30 mg BID subcutaneously) failed to demonstrate noninferiority regarding the relative effect (relative risk), but demonstrated it based on absolute risk difference (Table 3). The efficacy of apixaban in acute treatment/recurrence prevention in patients with VTE was demonstrated by noninferiority to a standard procedure (enoxaparin followed by titrated warfarin) regarding recurrent VTE or VTE-related deaths, whereas extended prevention efficacy was demonstrated through superiority to placebo regarding all-cause mortality or incidence of symptomatic recurrent VTE (Table 3). On the other hand, the attempt to demonstrate superior efficacy of a 30-day apixaban regimen vs in-hospital enoxaparin in reduction of 30-day incidence of VTE or VTE-related death in medically ill patients failed (Table 3).

\section{Safety of apixaban for VTE General overview}

Nonclinical pharmacology and toxicology safety studies have not indicated any particular safety signal that would raise a concern about the safety of apixaban with doses selected for human studies, apart from the expectations of increased risk of bleeding. During clinical development, some concerns arose related to its potential to cause liver injury. However, the overall experience in clinical trials in the approved, tested, but not approved and currently evaluated indications (beyond VTE) demonstrated that apixaban was not hepatotoxic. ${ }^{4-6,17,18}$ In a trial of apixaban for extended treatment (prophylaxis) of VTE (Table 3), apixaban $2.5 \mathrm{mg}$ BID or $5 \mathrm{mg}$ BID was comparable to placebo regarding all adverse events (type, incidence, severity), apart from a trend toward a greater incidence of bleeding. ${ }^{50}$ Therefore, as with other DOACs, the risk of bleeding is the only specific safety concern associated with the use of apixaban in the VTE setting.

\section{Risk of bleeding in clinical trials Patient exposure}

The main features of clinical trials of apixaban in the VTE setting are depicted in Table 3. Table 4 summarizes data on exposure to apixaban and control treatments in these trials. The number of patients differs from that in Table 3 , since safety assessment refers to "safety data sets", ie, all patients who received at least one dose of the assigned treatments. Overall, 14,680 patients were exposed to apixaban over different treatment periods: 9,121 to enoxaparin, mainly 40 mg QD (80\%); 2,966 to warfarin, almost exclusively (95\%) after initial short-term low-MW heparin (LMWH) treatment with dose titration to INR 2.0-3.0; and 858 to placebo (Table 4).

\section{Phase II dose-ranging trials}

Dose-ranging trials (prevention of VTE in TKA patients, acute treatment of VTE, prevention of VTE in cancer patients) provided no signal of dose dependence of adverse effects of apixaban between $2.5 \mathrm{mg}$ BID/5 mg QD and $10 \mathrm{mg}$ BID/20 mg QD (Table 5). All-cause mortality, incidence of serious adverse events, major

Table 4 Exposure to apixaban and control treatments in Phase II and Phase III randomized, double-blind, parallel-group, controlled trials in the setting of prophylaxis/treatment of VTE (study details depicted in Table 3): number of patients who received at least one dose of the assigned treatments ("safety data sets")

\begin{tabular}{|c|c|c|c|c|c|c|c|c|c|c|c|}
\hline \multirow[t]{2}{*}{ Indication, trial phase } & \multicolumn{6}{|c|}{ Apixaban (mg) } & \multicolumn{2}{|c|}{ Enoxaparin (mg) } & \multicolumn{2}{|c|}{$\begin{array}{l}\text { Warf/LMWH- } \\
\text { Warf (INR) }\end{array}$} & \multirow[t]{2}{*}{ PBO } \\
\hline & 2.5 BID & 5 QD & 5 BID & 10 QD & IO BID & 20 QD & 30 BID & 40 QD & $1.8-3.0$ & $2.0-3.0$ & \\
\hline TKA, I0-14 days, II,44 & 154 & $|5|$ & 153 & 155 & 153 & $15 \mid$ & 149 & - & $15 \mid$ & - & - \\
\hline TKA, I0-I4 days, IIII,45 & 1,596 & - & - & - & - & - & $\mathrm{I}, 588$ & - & - & - & - \\
\hline TKA, I0-I4 days, IIII,46 & $|, 50|$ & - & - & - & - & - & - & $\mathrm{I}, 508$ & - & - & - \\
\hline THA, 32-38 days, $111^{4,47}$ & 2,673 & - & - & - & - & - & - & 2,659 & - & - & - \\
\hline Acute VTE, 84-9I days, II,48 & - & - & 128 & - & 133 & 124 & - & - & - & 126 & - \\
\hline Acute VTE, 6 months, III ${ }^{5,49}$ & - & - & $2,676^{\mathrm{b}}$ & - & $2,676^{b}$ & - & - & - & - & $2,689^{b}$ & - \\
\hline Extended VTE, ${ }^{c}$ I year, IIII,50 & 840 & - & 815 & - & - & - & - & - & - & - & 829 \\
\hline Cancer, 3 months, $\mathrm{II}^{7}$ & - & 32 & - & 29 & - & 32 & - & - & - & - & 29 \\
\hline Medically ill, 30 days, $1 I^{8}$ & 3,184 & - & - & - & - & - & - & 3,217 & - & - & - \\
\hline Total & 9,948 & 183 & 3,772 & 184 & 286 & 307 & $\mathrm{I}, 737$ & 7,384 & $|5|$ & 2,815 & 858 \\
\hline
\end{tabular}

Notes: aUsed as mono-treatment titrated to INR I.8-3.0 to prevent VTE after TKA or to 2.0-3.0 following initial treatment with LMWH in acute treatment of VTE. ' apixaban regimen was $10 \mathrm{mg}$ BID for the first 7 days, followed by $5 \mathrm{mg}$ BID to a total of 6 months; control treatment was LMWH for the first 7 days, ie, to INR 2.0-3.0 followed by titrated warfarin. 'Extended (after the initial 6-12 months) prophylactic treatment. Dash indicates that the dose was not evaluated in this setting.

Abbreviations: INR, international normalized ratio; LMWH, low-molecular-weight heparin; PBO, placebo; THA, total-hip arthroplasty; TKA, total-knee arthroplasty; VTE, venous thromboembolism; Warf, warfarin. 
Table 5 Main safety outcomes in Phase II dose-ranging randomized double-blind controlled trials of apixaban in the setting of prophylaxis/treatment of VTE (percentage of safety population)

\begin{tabular}{|c|c|c|c|c|c|c|c|c|c|c|c|}
\hline \multirow[t]{2}{*}{ Trial/outcomes } & \multicolumn{6}{|c|}{ Apixaban (mg) } & \multicolumn{2}{|c|}{ Enoxaparin (mg) } & \multicolumn{2}{|c|}{$\begin{array}{l}\text { Warf/LMWH- } \\
\text { Warf (INR) }\end{array}$} & \multirow[t]{2}{*}{ PBO } \\
\hline & 2.5 BID & 5 QD & 5 BID & I 0 QD & IO BID & 20 QD & 30 BID & 40 QD & I.8-3.0 & $2.0-3.0$ & \\
\hline \multicolumn{12}{|l|}{ TKA, I0-I4 days d,44 $^{4,}$} \\
\hline All-cause mortality & 0.6 & 0 & 0 & 0 & 0 & 0 & 0 & - & 0 & - & - \\
\hline Major bleeding & 0 & 2.6 & 2.6 & 0.6 & 2.6 & 3.3 & 0 & - & 0 & - & - \\
\hline CRNM bleeding & 0 & 0 & 0 & 0.6 & 0 & 0 & 1.3 & - & 0 & - & - \\
\hline At least one SAE & 7.8 & 13.2 & 5.9 & 9.0 & 7.8 & 8.6 & 6.7 & - & 6.0 & - & - \\
\hline Myocardial infarction & 1.2 & 0.7 & 0 & 0 & 0 & 0 & 0 & - & 0.7 & - & - \\
\hline Stroke & 0.7 & 0.7 & 0.7 & 0.7 & 0 & 0.7 & 0 & - & 0 & - & - \\
\hline \multicolumn{12}{|c|}{ Acute VTE, 84-9 I days $\mathbf{s}^{5,48}$} \\
\hline All-cause mortality & - & - & 2.3 & - & 0.7 & 0.8 & - & - & - & 0 & - \\
\hline Major bleeding & - & - & 0.8 & - & 0 & 1.6 & - & - & - & 0 & - \\
\hline CRNM bleeding & - & - & 7.8 & - & 4.5 & 7.0 & - & - & - & 7.8 & - \\
\hline At least one SAE & - & - & NR & - & NR & NR & - & - & - & NR & - \\
\hline Myocardial infarction & - & - & NR & - & NR & NR & - & - & - & NR & - \\
\hline Stroke & - & - & NR & - & NR & NR & - & - & - & NR & - \\
\hline \multicolumn{12}{|l|}{ Cancer, 3 months ${ }^{7}$} \\
\hline All-cause mortality & - & 3.1 & - & 0 & - & 0 & - & - & - & - & 6.9 \\
\hline Major bleeding & - & 0 & - & 0 & - & 6.3 & - & - & - & - & 3.4 \\
\hline CRNM bleeding & - & 3.1 & - & 3.4 & - & 6.3 & - & - & - & - & 0 \\
\hline At least one SAE & - & $N R$ & - & NR & - & $N R$ & - & - & - & - & NR \\
\hline Myocardial infarction & - & NR & - & NR & - & NR & - & - & - & - & NR \\
\hline Stroke & - & NR & - & NR & - & NR & - & - & - & - & NR \\
\hline
\end{tabular}

Note: Dash indicates that the dose was not evaluated in this setting.

Abbreviations: CRNM, clinically relevant nonmajor (bleeding); INR, international normalized ratio; LMWH, low-molecular-weight heparin; NR, not reported; PBO, placebo; SAE, serious adverse event; TKA, total-knee arthroplasty; VTE, venous thromboembolism; Warf, warfarin.

bleeding, clinically relevant nonmajor (CRNM) bleeding, myocardial infarction, and stroke were comparably low across the tested doses and control treatments (warfarin, LMWH followed by warfarin or placebo). However, as already mentioned (see Table 2), a PK-PD model based on data from Phase II trials in TKA and treatment of VTE indicated a higher risk of major bleeding with increasing total exposure.

\section{Pivotal Phase III trials}

In pivotal trials of apixaban for VTE prevention in patients undergoing major orthopedic surgery (the ADVANCE program), ${ }^{4,4-47}$ all-cause mortality was considered as both a part of the composite primary efficacy end point (Table 3 ) and a safety outcome. ${ }^{4}$ As depicted in Table 6, only sporadic deaths occurred during treatment ( $\pm 2-3$ days after the last dose) and over a subsequent 60-day follow-up in apixabantreated and enoxaparin-treated patients. In ADVANCE-3, 4,49 relative risk-point estimates for all-cause death during the treatment period and overall duration of the study (plus follow-up) indicated a trend toward higher mortality in apixaban-treated patients (Table 6). However, there were only a few events: in the apixaban arm, three patients died on treatment and two during follow-up, whereas in the enoxaparin arm, one patient died on treatment and one during follow-up. The only death adjudicated as VTE- or bleeding-related referred to an apixaban-treated patient who died of PE on day 9 of treatment. Other causes of death in the apixaban arm were abdominal compartment syndrome (one), colonic neoplasm (one), ileal perforation (one), and pancreatic cancer (one). In the enoxaparin arm, causes of death were fat embolism (one) on treatment and stroke (one) during follow-up.,49 Overall, the slightly higher allcause mortality in the apixaban arm was most likely due to chance. This is supported by the fact that no such trend was seen in trials in TKA patients or in acute VTE treatment vs enoxaparin followed by titrated warfarin (AMPLIFY trial $)^{5,49}$ (Table 6), whereas in the extended VTE prophylaxis (AMPLIFY-EXT trial) ${ }^{5,50}$ all-cause mortality over a 1-year treatment period was lower with apixaban (cumulatively 2.5 $\mathrm{mg}$ BID and $5 \mathrm{mg}$ BID) than with placebo (Table 6).

In all trials, ${ }^{4,5,8,45-47,49,50}$ bleeding events were defined in line with the criteria of the International Society on Thrombosis and Hemostasis (the same or slightly modified definitions were used in all depicted Phase II and III trials). ${ }^{51}$ The rate of major bleeding overall was low across all trials (Table 6). In acute conditions, ie, orthopedic surgery, acute VTE, and acutely medically ill patients, the rate of 
Table 6 Main safety outcomes in Phase III trials of Apix for VTE (percentage of safety population)

\begin{tabular}{|c|c|c|c|c|c|c|c|c|c|c|c|c|c|}
\hline & \multicolumn{2}{|c|}{ ADVANCE ${ }^{4,45}$} & \multicolumn{2}{|c|}{ ADVANCE-2 $2^{4,46}$} & \multicolumn{2}{|c|}{ ADVANCE-34,47 } & \multicolumn{2}{|c|}{ AMPLIFY5,49 } & \multicolumn{3}{|c|}{ AMPLIFY-EXT' } & \multicolumn{2}{|c|}{ ADOPT $^{8}$} \\
\hline & \multirow{2}{*}{\multicolumn{2}{|c|}{$\begin{array}{l}\text { TKA, 10-14 } \\
\text { days, follow-up }\end{array}$}} & \multirow{2}{*}{\multicolumn{2}{|c|}{$\begin{array}{l}\text { TKA, I0-14 } \\
\text { days, follow-up }\end{array}$}} & \multirow{2}{*}{\multicolumn{2}{|c|}{$\begin{array}{l}\text { THA, 32-38 days, } \\
\text { follow-up }+60\end{array}$}} & \multirow{2}{*}{\multicolumn{2}{|c|}{$\begin{array}{l}\text { Acute VTE, } \\
6 \text { months, follow- }\end{array}$}} & \multicolumn{3}{|c|}{ Extended VTE after 6-12 } & \multicolumn{2}{|c|}{ Medically ill, } \\
\hline & & & & & & & & & month & s, I yea & r, follow-up & 30 day & , follow-up \\
\hline & $+60 \mathrm{da}$ & & $+60 d$ & & days & & up +3 & days & $+30 \mathrm{da}$ & & & $+60 \mathrm{da}$ & \\
\hline & \multicolumn{2}{|c|}{ Apix $2.5 \mathrm{mg}$} & \multicolumn{2}{|c|}{ Apix $2.5 \mathrm{mg}$ BID } & \multicolumn{2}{|c|}{ Apix $2.5 \mathrm{mg}$} & \multicolumn{2}{|c|}{ Apix 10 mg BID 7} & \multicolumn{3}{|c|}{ Apix 2.5 (low)/5 mg (high) } & \multicolumn{2}{|c|}{ Apix $2.5 \mathrm{mg}$ BID } \\
\hline & \multicolumn{2}{|c|}{ BID vs Enox } & \multicolumn{2}{|c|}{ vs Enox 40 mg } & \multicolumn{2}{|c|}{ BID vs Enox } & \multirow{2}{*}{\multicolumn{2}{|c|}{$\begin{array}{l}\text { days } \rightarrow 5 \mathrm{mg} \text { BID } \\
\text { vs Enox/Warf }\end{array}$}} & \multirow{2}{*}{\multicolumn{3}{|c|}{ BID vs placebo }} & \multirow{2}{*}{\multicolumn{2}{|c|}{$\begin{array}{l}\text { vs Enox } 40 \mathrm{mg} \\
\text { QD } 10 \text { days }\end{array}$}} \\
\hline & $30 \mathrm{mg}$ & & QD & & $40 \mathrm{mg}$ & QD & & & & & & & \\
\hline & Apix & Ctrl & Apix & Ctrl & Apix & Ctrl & Apix & Ctrl & $\begin{array}{l}\text { Apix } \\
\text { low }\end{array}$ & $\begin{array}{l}\text { Apix } \\
\text { high }\end{array}$ & Ctrl & Apix & Ctrl \\
\hline \multicolumn{14}{|l|}{ All deaths } \\
\hline Treatment & 0.2 & 0.2 & 0.1 & 0 & 0.1 & $<0.1$ & 1.5 & 1.9 & 0.8 & 0.5 & 1.7 & NR & NR \\
\hline Follow-up & 0 & 0.2 & 0.1 & 0.1 & 0.1 & $<0.1$ & 0.3 & 0.2 & 0.1 & 0.4 & 0.2 & NR & NR \\
\hline RR treatment ${ }^{c}$ & \multicolumn{2}{|c|}{$0.99(0.13-7.45)$} & \multicolumn{2}{|l|}{-} & \multicolumn{2}{|c|}{$2.97(0.24-156)$} & 0.71( & $.59-1.22)$ & All Api & ix 0.39 & $(0.16-0.93)$ & - & \\
\hline RR total ${ }^{c}$ & $0.50(C$ & 08-2.34) & $2.0(0$ & $1-118)$ & 2.48 & $.4 I-26.0)$ & 0.83( & $.56-1.24)$ & All Api & ix 0.47 & $(0.22-1.01)$ & - & \\
\hline Major bleed & & & & & & & & & & & & & \\
\hline Treatment & 0.7 & 1.4 & 0.6 & 0.9 & 0.8 & 0.7 & 0.6 & 1.8 & 0.2 & 0.1 & 0.5 & 0.5 & 0.2 \\
\hline RR treat ${ }^{c}$ & 0.50 & $22-1.07)$ & 0.65 & $.25-1.60)$ & $1.21(C$ & $.62-2.40)$ & 0.31( & $.17-0.55)$ & All Api & ix 0.37 & $(0.05-2.18)$ & $2.58(I$ & $.02-7.24)$ \\
\hline CRNMB & & & & & & & & & & & & & \\
\hline Treatment & 2.2 & 3.0 & 2.9 & 3.8 & 4.1 & 4.5 & 3.8 & 8.0 & 3.0 & 4.2 & 2.3 & 2.2 & 1.9 \\
\hline RR treat ${ }^{c}$ & 0.74 & $46-1.17)$ & 0.76 & $.50-1.15)$ & 0.90 & $.69-1.17)$ & 0.48( & $.38-0.60)$ & All Api & ix 1.53 & $(0.90-2.72)$ & $1.16(0$ & $.8 I-1.66)$ \\
\hline Any SAE & & & & & & & & & & & & & \\
\hline Total time & 8.5 & 8.6 & 6.0 & 7.0 & NR & NR & $15.6^{\mathrm{b}}$ & $15.2^{\mathrm{b}}$ & $13.3^{b}$ & $13.2^{\mathrm{b}}$ & $19.1^{\mathrm{b}}$ & NR & NR \\
\hline RR total ${ }^{c}$ & 0.99 & $77-1.26)$ & 0.92 & $.68-1.25)$ & - & & 1.02( & $.89-1.17)$ & All Api & ix 0.69 & $(0.56-0.86)$ & - & \\
\hline MI & & & & & & & & & & & & & \\
\hline Total time & 0.1 & 0.3 & $<1.0$ & $<0.1$ & 0.3 & 0.2 & 0.2 & 0.15 & $0.2^{\mathrm{b}}$ & $0.4^{b}$ & $0.5^{\mathrm{b}}$ & NR & NR \\
\hline RR total ${ }^{c}$ & 0.40 & 04-2.43) & 1.00 & $.0 \mathrm{I}-79)$ & 2.23 & $.61-9.91)$ & 1.51( & $.36-7.26)$ & All Api & ix 0.63 & $(0.13-3.16)$ & - & \\
\hline Stroke & & & & & & & & & & & & & \\
\hline Total time & 0 & 0.1 & 0.1 & 0 & 0.1 & 0.2 & $0.5^{\mathrm{b}}$ & $0.3^{\mathrm{b}}$ & $0.1^{\mathrm{b}}$ & $0.1^{b}$ & $0.6^{\mathrm{b}}$ & NR & NR \\
\hline RR total ${ }^{c}$ & - & & - & & 0.60 & $.09-3.06)$ & 1.51 & $.57-4.25)$ & All Api & $\mathrm{ix} 0.30$ & $(0.02-1.22)$ & - & \\
\hline
\end{tabular}

Notes: aStandard initial therapeutic dose of enoxaparin with concurrent titration of warfarin to international normalized ratio $2.0-3.0$, then titrated warfarin; bduring treatment (follow-up data not available). 'Relative risk is given with $95 \%$ confidence intervals in parenthesis. Dash indicates that the RR could not be calculated. Arrow means followed by.

Abbreviations: SAE, serious adverse event; Apix, apixaban; CRNMB, clinically relevant nonmajor bleeding; Ctrl, control; Enox, enoxaparin; MI, myocardial infarction; NR, not reported; RR, relative risk; THA, total hip arthroplasty; TKA, total knee arthroplasty; VTE, venous thromboembolism; Warf, warfarin.

major bleeding across the apixaban arms was consistently between $0.5 \%$ and $0.8 \%$ (Table 6 ), and was lower, practically negligible, in the extended prophylaxis of VTE: $0.2 \%$ and $0.1 \%$ over 1 year in the $2.5 \mathrm{mg}$ BID and $5.0 \mathrm{mg}$ BID arms (Table 6). When the rates in the control treatments were relatively high, eg, $1.4 \%$ with enoxaparin $30 \mathrm{mg}$ BID in prevention of VTE in TKA patients ${ }^{4,45}$ or $1.8 \%$ in the acute treatment of VTE with enoxaparin and subsequent titrated warfarin $^{49}$ (mean percentage time in therapeutic range [TTR] was $60.9 \%$, median $59.1 \%),{ }^{5}$ then the rates with apixaban tended to be lower (TKA) or were clearly lower, indicating a benefit of apixaban. On the other hand, when the control rates were low, eg, with enoxaparin $40 \mathrm{mg}$ QD in acutely medically ill patients, the rates with apixaban were significantly higher (Table 6 ) ${ }^{8} \mathrm{~A}$ similar pattern is observed considering CRNM bleedings: incidence was lower with apixaban vs enoxaparin followed by warfarin in the acute treatment of $\mathrm{VTE}^{5,49}$ and tended to be lower with $2.5 \mathrm{mg}$ BID apixaban vs enoxaparin $30 \mathrm{mg}$ BID in VTE prevention in one trial in TKA patients, ${ }^{4,45}$ whereas no difference was observed in other trials (Table 6).

In the active-controlled trials in approved indications, the incidence of serious adverse events was comparable for apixaban vs control treatments (Table 6), whereas it was lower for apixaban $2.5 \mathrm{mg}$ BID or $5 \mathrm{mg}$ BID (or cumulatively) vs placebo in extended prophylaxis of VTE (Table 6). The reported incidence of myocardial infarction and stroke was very low across all trials, with no clear indication of benefits or harms of apixaban vs control (Table 6). It should be noted that in all trials, occurrence/recurrence of VTE (or composite outcomes of all-cause- or VTE-related deaths and VTE) during follow-up periods after discontinuation of treatment did not differ between apixaban and control treatments (Table 3 ), and that no excess myocardial infarction, stroke, or any serious adverse event was observed with apixaban during the overall study duration, ie, including follow-up (Table 6), indicating no rebound hypercoagulation or prolonged anticoagulation after apixaban discontinuation. 


\section{Specifics related to prevention of VTE in major orthopedic surgery}

Within the European Union, two trials of apixaban for prevention of VTE in major orthopedic surgery are considered pivotal-ADVANCE-2 ${ }^{4,46}$ (TKA patients) and ADVANCE-3 $3^{4,47}$ (THA patients) - since they compared apixaban $2.5 \mathrm{mg}$ to a "standard European" enoxaparin schedule (40 mg QD). A prespecified subgroup analysis was performed for joint data $(8,454$ patients evaluated for bleeding), ${ }^{52}$ demonstrating consistently no difference between apixaban and enoxaparin regarding major bleeding on treatment across the age-groups $(<65$, $65-74$, and $\geq 75$ years), sex, body weight ( $<60$ or $>60 \mathrm{~kg}$ ), body mass index $\left(<25,25-29\right.$, and $\left.\geq 30 \mathrm{~kg} / \mathrm{m}^{2}\right)$ and creatinine clearance $(\leq 50,51-80$, and $>80 \mathrm{~mL} / \mathrm{min})$. A trial comparing apixaban to the "American enoxaparin protocol" (30 mg BID) in TKA patients provided no subgroup data. ${ }^{45}$ Even when prespecified, subgroup analyses are of limited meaning, as they typically lack power for the evaluated effect and even more so for the test of the interaction term. However, in consideration of the number of evaluated subjects, it is fair to say that there seems to be no relevant moderator of the risk of major bleeding associated with the use of apixaban in this setting.

While it might be tempting to try to estimate the overall effect of apixaban vs enoxaparin in the setting of VTE prevention in major orthopedic surgery using a meta-analytical approach, clinical heterogeneity should be taken into consideration (regardless of a possible statistical homogeneity): different enoxaparin protocols in TKA resulted in different control bleeding rates (Table 6), whereas TKA and THA settings differ in the standard duration of treatment. It thus seems that individual trial data, with their clinical particulars, are the best indicators of the relative effect of apixaban vs enoxaparin. Clinical inconsistency seems to present an even greater problem in attempts to compare DOACs indirectly. An early indirect comparison of dabigatran and rivaroxaban pointed out the problem of differences in TKA/THA protocols, enoxaparin schedules, adjudication criteria for VTE, and definitions and counting of bleeding events. ${ }^{53}$ The same was emphasized in a more recent network meta-analysis of dabigatran, rivaroxaban, and apixaban (all compared to enoxaparin) for VTE prevention in major orthopedic surgery ${ }^{54}$ Consequently, in VTE prevention vs enoxaparin $30 \mathrm{mg}$ BID in TKA patients, apixaban $2.5 \mathrm{mg}$ BID provided nonrelevantly different clinical efficacy (although the relative risk for the primary efficacy end point fell slightly over the limit of noninferiority; Table 3). The trial report ${ }^{45}$ suggested that at the same time, apixaban provided a benefit of less major or CRNM bleeding (using the pooled events). However, it seems more appropriate to consider major and CRNM bleedings separately, since their clinical relevance is different. Therefore, it appears plausible to state that in this setting, apixaban might confer a benefit of somewhat-lower risk of major bleeding and of CRNM bleeding. In comparison to enoxaparin $40 \mathrm{mg}$ QD in either TKA or THA patients, apixaban clearly yields better efficacy (Table 3), while at the same time it apparently does not increase the risk of either major or CRNM bleeding (Table 6).

On the other hand, a reliable and accurate evaluation of apixaban with respect to other DOACs in this setting will have to await direct comparative trials.

\section{Specifics related to acute treatment/prevention of recurrence in patients with VTE}

A prespecified subgroup analysis was also conducted in a trial of apixaban vs enoxaparin/warfarin for acute treatment of VTE (AMPLIFY). ${ }^{5,49}$ The apixaban vs control differences in the primary efficacy end point (overall noninferiority, Table 3 ) were consistent across age, sex, body weight, body mass index, renal function, timing of enoxaparin commencement, whether index event was PE or DVT, location of DVT, and extent of PE, and fell in most of these subgroups within the limit of noninferiority (except when the stratum or the number of events was small). The same was observed across the strata of TTR $(<51.5 \%, 51.5 \%-59 \%, 59.1 \%-68 \%$, and $>68 \%)$.

The difference in the risk of major bleeding was also consistent, indicating significant reduction (except in small strata/rare events) across the strata and clearly at all levels of TTR. Overall, in consideration of the size of the trial (and having in mind all the limitations of the subgroup analyses), as in the case of VTE prevention in orthopedics, it appears reasonable to conclude that there is no major moderator of the risk of major bleeding associated with the use of apixaban in this setting.

As recently reviewed by Bacchus and Schulman, ${ }^{55}$ several network (mixed-treatment) meta-analyses have attempted to indirectly compare the DOACs in this setting, but were limited by only partial inclusion of the major trials. However, even with all the relevant trials and all technical requirements met, exclusively indirect comparisons should be viewed as only exploratory (and not confirmatory) efforts. Three such analyses included all pivotal Phase III trials of apixaban, rivaroxaban, dabigatran, and edoxaban (all vs a standard LMWH-vitamin K antagonist treatment; $n=6$ ) to conclude no relevant difference between DOACs regarding efficacy, but the greatest reduction in major or major and CRNM bleedings with apixaban. ${ }^{56-58}$ A similar conclusion was drawn in a comprehensive network meta-analysis of 45 trials of all treatments for acute VTE. ${ }^{59}$ 


\section{Specifics related to extended prophylactic treatment of VTE}

Finally, consistent differences between apixaban $2.5 \mathrm{mg}$ or $5.0 \mathrm{mg}$ BID vs placebo in extended prophylactic treatment of VTE (AMPLIFY-EXT) ${ }^{5,50}$ were demonstrated regarding efficacy (prevention of recurrent VTE/VTE-related death) across age, sex, type of index event, body weight, body mass index, and renal function. Bleedings were considered a composite of major and CRNM bleedings, with a consistently nonsignificant difference vs placebo. Since the trial was relatively small (considering the low event rates, $\sim 800$ patients per treatment arm), some estimates were highly imprecise. However, the position and direction of point estimates and supportive data referring to acute treatment of VTE justify a claim that there seems to be no major moderator of the apixaban-associated bleeding risk in this indication. A network meta-analysis of 12 trials comparing different treatments (placebo/observation; low-dose aspirin, low-dose or titrated vitamin K antagonists, idraparinux, dabigatran, rivaroxaban, and apixaban) indicated that only apixaban (both doses) and aspirin did not increase the risk of major/CRNM bleeding (vs placebo/observation). The risk with apixaban was also significantly lower than with rivaroxaban, idraparinux, dabigatran, and vitamin K antagonists. ${ }^{60}$ Another network meta-analysis including the same 12 trials and an additional trial with ximelagatran vs placebo came to the same conclusion: apixaban $2.5 \mathrm{mg}$ or $5.0 \mathrm{mg}$ was the only treatment that did not increase the risk of major bleeding compared to placebo or observation. The estimated absolute risk difference, presented as a number of major bleeding episodes per 100 patients treated over 1 year, was -0.26 ( $95 \%$ confidence interval -0.32 to 0.2$)$ for apixaban $2.5 \mathrm{mg}$ BID and $-0.2(95 \%$ confidence interval -0.3 to 0.6 ) for apixaban $5.0 \mathrm{mg} \mathrm{BID} .{ }^{61}$

\section{A few considerations about safety in daily practice}

The first regulatory approval for apixaban was in 2011 for prevention of VTE in patients undergoing THA/TKA, and was followed by approval for stroke prevention in patients with NVAF in 2012 and approval for acute and extended treatment/prophylaxis of VTE in 2014. Considering its relatively brief history on the market, published data referring to apixaban's safety apart from the premarketing trials are sparse. As recently reviewed, however, the utilization of apixaban in daily practice is steadily increasing. ${ }^{62}$ In the period MayNovember 2014 in the US, 5.1\% of all prescriptions (new and refills) for anticoagulants were for apixaban (indicating an increase from a previous period), whereas when only new prescriptions were considered, $17.1 \%$ were for apixaban. ${ }^{62}$
The fact that the approved label (summary of the product characteristics) for apixaban has not undergone any major revision regarding safety (apart from the specific updates pertinent for each of the approved indications) suggests that its safety profile in regular use agrees with that delineated through premarketing trials.

As with anticoagulants in general, inappropriate use of apixaban may result in either highly undesirable lack of efficacy or equally serious harmful effects, and hence it is essential that it is used in line with the prescribing information (patient selection, assessment of hepatic and renal function, consideration of comedication and potential interactions, and appropriate dosing and compliance). A recent comprehensive review on various aspects of the use of DOACs identified several surveys demonstrating high prevalence $(10 \%-20 \%)$ of nonadherence to product information (eg, use of a lower dose of a drug in patients with an absolute contraindication, inappropriate concomitant use of DOACs and antiplatelets, and poor patient accountability for dispensed tablets). ${ }^{63}$ Besides the product information, professional guidelines in anesthesia, cardiology, surgery, and pulmonary medicine have developed strategies to handle DOACs in specific situations, eg, switching from DOACs to classical anticoagulants and vice versa or periprocedural management of patients undergoing regional anesthesia or surgery, and prescribing physicians should be aware of them..$^{64}$

Although apixaban, in common with other DOACs, does not require continuous coagulation monitoring, in certain situations (eg, a need for emergency procedures) a rapid and reliable assessment of its anticoagulant activity (ie, risk of intervention-provoked bleeding) would be desirable. ${ }^{65}$ In the comprehensive pharmacological assessment of apixaban, a strong direct linear relationship has been established between apixaban plasma concentrations (exposure) and anti-Xa activity assessed by a chromogenic assay and between exposure and the risk of major bleeding (see Table 2). A less firm relationship was observed between plasma apixaban concentrations and modified prothrombin time, and particularly between plasma apixaban concentrations and prothrombin time, INR, and activated partial thromboplastin time. These tests are thus uninformative in regard to the level of anticoagulant activity of apixaban.$^{65}$ It has been repeatedly demonstrated that chromogenic anti-Xa assays calibrated with specific apixaban calibrators can accurately measure apixaban (validated against liquid chromatography-tandem mass spectrometry direct concentration measurements) across a wide range of concentrations, but chromogenic anti-Xa assays are not readily available and critical cutoff values clearly predictive of the risk of bleeding have not been defined. ${ }^{65,66}$ 
Finally, management of apixaban-associated bleedings is an important aspect of the drug's safe use. The standard general measures, such as transient drug discontinuation (a few doses), and local measures (eg, mechanical compression) suffice for the management of minor bleedings. Major or life-threatening bleedings require complete drug discontinuation, mechanical compression, surgical hemostasis, transfusion (red blood cells, platelets [if antiplatelets are concomitantly used]) and the use of activated charcoal if apixaban was ingested 2-6 hours previously. For the time being, there is no specific highly effective antidote for apixaban. As with other fXa inhibitors, dialysis is useless, since apixaban is highly protein-bound, and prothrombin-complex concentrates, FEIBA (factor eight inhibitor bypassing activity), or recombinant activated fVII have a limited efficacy. However, two drugs in development should be reasonably expected to provide reliable antagonism not only against apixaban but also against other fXa inhibitors: recombinant human $\mathrm{fXa}$ (andexanet alfa) in vitro and in early human studies rapidly reverses the effects of apixaban (and other direct fXa inhibitors) by competitively binding them; ciraparantag, a small synthetic molecule, binds heparins, dabigatran, and direct $\mathrm{fXa}$ inhibitors through hydrogen bonding and in vitro reverses their effect. ${ }^{67} \mathrm{~A}$ specific issue yet to be resolved in order to get a full view on the safety profile of apixaban in the VTE setting is to gain experience with its use in patient subsets that do not fully fit the description of patients included in the premarketing clinical trials.

\section{Conclusion}

Apixaban is a novel DOAC: a direct fXa inhibitor. In an extensive premarketing clinical development program, apixaban was evaluated with respect to the standard recommended treatments and displayed superior efficacy with no excess risk of bleeding in prevention of VTE in patients undergoing THA or TKA. In patients with acute VTE (treatment), apixaban showed noninferior efficacy with reduced bleeding risk. Finally, apixaban was shown to be effective with no excess bleeding risk compared to placebo in extended VTE prophylaxis. To what extent this favorable safety profile will be transferred to daily practice depends largely on its adequate use.

\section{Disclosure}

The author reports no conflicts of interest in this work.

\section{References}

1. Wong PC, Pinto DJ, Zhang D. Preclinical discovery of apixaban, a direct and orally bioavailable factor Xa inhibitor. J Thromb Thombolysis. 2011;31:478-492.
2. European Medicines Agency. Eliquis [summary of product characteristics]. Available from: http://www.ema.europa.eu/docs/en_GB/ document_library/EPAR_-_Product_Information/human/002148/ WC500107728.pdf. Accessed June 15, 2015.

3. Eliquis [prescribing information]. Princeton (NJ): Bristol-Myers Squibb; 2015. Available from: http://packageinserts.bms.com/pi/pi_eliquis.pdf. Accessed June 15, 2015.

4. European Medicines Agency. Assessment report for Eliquis. Available from: http://www.ema.europa.eu/docs/en_GB/document_library/ EPAR_-_Public_assessment_report/human/002148/WC500107726. pdf. Accessed June 15, 2015.

5. European Medicines Agency. Assessment report for Eliquis [variation]. 2014. Available from: http://www.ema.europa.eu/docs/ en_GB/document_library/EPAR_-_Assessment_Report_-_Variation/ human/002148/WC500173870.pdf. Accessed June 15, 2015.

6. European Medicines Agency. Assessment report for Eliquis [variation]. 2012. Available from: http://www.ema.europa.eu/docs/ en_GB/document_library/EPAR_-_Assessment_Report_-_Variation/ human/002148/WC500136575.pdf. Accessed June 15, 2015.

7. Levine $\mathrm{MN}, \mathrm{Gu} \mathrm{C}$, Liebman HA, et al. A randomized phase II trial of apixaban for the prevention of thromboembolism in patients with metastatic cancer. J Thromb Haemost. 2012;10:807-814.

8. Goldhaber SZ, Leizorovicz A, Kakkar AJ, et al. Apixaban versus enoxaparin for thromboprophylaxis in medically ill patients. $N$ Engl J Med. 2011;365:2167-2177.

9. Alexander JH, Becker RC, Bhatt DL, et al. Apixaban, an oral, direct, selective factor Xa inhibitor, in combination with antiplatelet therapy after acute coronary syndrome: results of the Apixaban for Prevention of Acute Ischemic and Safety Events (APPRAISE) trial. Circulation. 2009;119:2877-2885.

10. Alexander JH, Lopes RD, James S, et al. Apixaban with antiplatelet therapy after acute coronary syndrome. N Engl J Med. 2011;365:699-708.

11. Ogawa H, Goto S, Matsuzaki M, Hiro S, Shima D. Randomized, doubleblind trial to evaluate the safety of apixaban with antiplatelet therapy after acute coronary syndrome in Japanese patients (APPRAISE-J). Circ J. 2013;77:2341-2348.

12. Konstantinides S, Torbicki A, Agnelli G, et al. 2014 ESC guidelines on the diagnosis and management of acute pulmonary embolism. Eur Heart J. 2014;35:3033-3069, 3069a-3069k.

13. Kearon C, Akl E, Comerota AJ, et al. Antithrombotic therapy for VTE disease. Chest. 2012;141:e419S-e494S.

14. Wong PC, Crain EJ, Xin B, et al. Apixaban, an oral, direct and highly selective factor $\mathrm{Xa}$ inhibitor: in vitro, antithrombotic and antihemostatic studies. J Thromb Haemost. 2008;6:820-829.

15. Jiang XS, Crain EJ, Luettgen JM, Schumacher WA, Wong PC. Apixaban, an oral direct factor Xa inhibitor, inhibits human clot-bound factor Xa activity in vitro. Thromb Haemost. 2008;101:780-782.

16. Escolar G, Fernandez-Gallego V, Arellano-Rodrigo E, et al. Reversal of apixaban induced alterations in hemostasis by different coagulation factor concentrates: significance of studies in vitro with circulating human blood. PloS One. 2013;8:e78696.

17. Center for Drug Evaluation and Research. Application number 2012155Orig1s000. Clinical pharmacology and biopharmaceutics review(s). 2012. Available from: http://www.accessdata.fda.gov/drugs atfda_docs/nda/2012/202155Orig1s000ClinPharmR.pdf. Accessed June 15, 2015.

18. Center for Drug Evaluation and Research. Application number 2012155Orig1s002. Clinical pharmacology and biopharmaceutics review(s). 2013. Available from: http://www.accessdata.fda.gov/drugs atfda_docs/nda/2014/202155Orig1s002ClinPharmR.pdf. Accessed June 15, 2015.

19. Barrett YC, Wang Z, Frost C, Shenker A. Clinical laboratory measurement of direct factor $\mathrm{Xa}$ inhibitors: anti-Xa assay is preferable to prothrombin time assay. Thromb Haemost. 2010;104:1263-1271.

20. Barrett YC, Wang J, Song Y, et al. A randomised assessment of the pharmacokinetic, pharmacodynamics and safety interaction between apixaban and enoxaparin in healthy subjects. Thromb Haemost. 2012;107:916-924. 
21. Cui Y, Song Y, Wang J, et al. Single- and multiple-dose pharmacokinetics, pharmacodynamics, and safety of apixaban in Chinese subjects. Clin Pharmacol. 2013;5:177-184.

22. Hanna MS, Mohan P, Knabb R, Gupta E, Frost C, Lawrence JH. Development of apixaban: a novel anticoagulant for prevention of stroke in patients with atrial fibrillation. Ann NY Acad Sci. 2013;1329: 93-106.

23. Frost C, Wang J, Nepal S, et al. Apixaban, an oral, direct factor Xa inhibitor: single dose safety, pharmacokinetics, pharmacodynamics and food effect in healthy subjects. Br J Clin Pharmacol. 2012;75:476-487.

24. Frost C, Nepal S, Wang J, et al. Safety, pharmacokinetics and pharmacodynamics of multiple oral doses of apixaban, a factor Xa inhibitor, in healthy subjects. Br J Clin Pharmacol. 2013;76:776-786.

25. Frost C, Shenker A, Gandhi MD, et al. Evaluation of the effect of naproxen on the pharmacokinetics and pharmacodynamics of apixaban. Br J Clin Pharmacol. 2014;78:877-885.

26. Frost $\mathrm{C}$, Song Y, Barrett YC, et al. A randomized direct comparison of the pharmacokinetics and pharmacodynamics of apixaban and rivaroxaban Clin Pharmacol. 2014;6:179-187.

27. Frost CE, Byon W, Song Y, et al. Effect of ketoconazole and diltiazem on the pharmacokinetics of apixaban, an oral direct factor Xa inhibitor. Br J Clin Pharmacol. 2015;79:838-846.

28. Frost C, Song Y, Shenker A, et al. Effects of age and sex on the singledose pharmacokinetics and pharmacodynamics of apixaban. Clin Pharmacokinet. 2015;54:651-662.

29. Frost C, Boyd RA. The contribution of apixaban renal clearance to total clearance. J Thromb Thrombolysis. 2015;40:521-522.

30. Frost C, Nepal S, Byon W, et al. Randomized, blinded, placebo- and positive-controlled crossover study to determine the effect of multiple doses of apixaban on the QTc interval. J Clin Pharmacol. 2015;55: 549-555.

31. Leil TA, Feng Y, Zhang L, Paccaly A, Mohan P, Pfister M. Quantification of apixaban's therapeutic utility in prevention of venous thromboembolism: selection of phase III trial dose. Clin Pharmacol Ther. 2010;88:375-382.

32. Raghavan N, Frost CE, Yu ZG, et al. Apixaban metabolism and pharmacokinetics after oral administration in humans. Drug Metab Dispos. 2009;37:74-81.

33. Upreti VV, Song Y, Wang J, et al. Effect of famotidine on the pharmacokinetics of apixaban, an oral direct factor Xa inhibitor. Clin Pharmacol. 2013;5:59-66

34. Upreti VV, Wang J, Barrett YC et al. Effect of extremes of body weight on the pharmacokinetics, pharmacodynamics, safety and tolerability of apixaban in healthy subjects. Br J Clin Pharmacol. 2013;76:908-916.

35. Wang L, Raghavan N, He K, et al. Sulfation of $O$-demthyl apixaban: enzyme identification and species comparison. Drug Metab Dispos. 2009;37:802-808

36. Wang L, Zhang D, Raghavan N, et al. In vitro assessment of metabolic drug-drug interaction potential of apixaban through cytochrome P450 phenotyping, inhibition and induction studies. Drug Metab Dispos. 2010;38:448-458.

37. Wang L, He K, Maxwell B, et al. Tissue distribution and elimination of $\left[{ }^{14} \mathrm{C}\right]$ apixaban in rats. Drug Metab Dispos. 2011;39:256-264.

38. Wang X, Mondal S, Wang J, et al. Effect of activated charcoal on apixaban pharmacokinetics in healthy subjects. Am J Cardiovasc Drugs. 2014; $14: 147-154$.

39. Wong PC, Watson CA, Crain EJ. Arterial antithrombotic and bleeding time effects of apixaban, a direct factor Xa inhibitor, in combination with antiplatelet therapy in rabbits. J Thromb Haemost. 2008;6: 1736-1741.

40. Yamahira N, Frost C, Fukase H, et al. Safety, tolerability, pharmacokinetics and pharmacodynamics of multiple doses of apixaban in healthy Japanese male subjects. Int J Clin Pharmcol Ther. 2014;52:564-573.

41. Zhang D, He K, Raghavan N, et al. Comparative metabolism of ${ }^{14} \mathrm{C}$-labeled apixaban in mice, rats, rabbits, dogs and humans. Drug Metab Dispos. 2009;37:1738-1748.
42. Zhang D, Frost $\mathrm{CE}, \mathrm{He} \mathrm{K}$, et al. Investigating the enteroenteric recirculation of apixaban, a factor $\mathrm{Xa}$ inhibitor: administration of activate charcoal to bile duct-cannulated rats and dogs receiving an intravenous dose and use of drug transporter knockout rats. Drug Metab Dispos. 2013;41:906-915.

43. Zhang D, He K, Herbst JJ, et al. Characterization of efflux transporters involved in distribution and disposition of apixaban. Drug Metab Dispos. 2013;41:827-835.

44. Lassen MR, Davidson B1, Gallus A, Pineo G, Ansell J, Deitchman D. The efficacy and safety of apixaban, an oral, direct factor Xa inhibitor, as thromboprophylaxis in patients following total knee replacement. J Thromb Haemost. 2007;5:2368-2375.

45. Lassen MR, Raskob GE, Gallus A, Pineo G, Chen D, Portman RJ. Apixaban or enoxaparin for thromboprophylaxis after knee replacement. N Engl J Med. 2009;361:594-604.

46. Lassen MR, Raskob GE, Gallus A, Pineo G, Chen D, Hornick P. Apixaban versus enoxaparin for thromboprophylaxis after knee replacement (ADVANCE-2): a randomised double-blind trial. Lancet. 2010;375:807-815.

47. Lassen MR, Gallus A, Raskob GE, Pineo G, Chen D, Ramirez LM. Apixaban versus enoxaparin for thromboprophylaxis after hip replacement. N Engl J Med. 2010;363:2487-2498.

48. Buller H, Deitchman D, Prins M, Segers A. Efficacy and safety of the oral direct factor Xa inhibitor apixaban for symptomatic deep vein thrombosis. The Boticelli DVT dose-ranging study. J Thromb Haemost. 2008;6:1313-1318.

49. Agnelli G, Buller HR, Cohen A, et al. Oral apixaban for the treatment of acute venous thromboembolism. N Engl J Med. 2013;369:799-808.

50. Agnelli G, Buller HR, Cohen A, et al. Apixaban for extended treatment of venous thromboembolism. N Engl J Med. 2013;368:699-708.

51. Schulman S, Kearon C. Definition of major bleeding in clinical investigations of antihemostatic medicinal products in non-surgical patients. J Thromb Haemost. 2005;3:692-694.

52. Pineo GF, Gallus AS, Raskob GE, et al. Apixaban after hip or knee arthroplasty versus enoxaparin: efficacy and safety in key clinical subgroups. J Thromb Haemost. 2013;11:444-451.

53. Trkulja V, Kolundžić R. Rivaroxaban vs dabigatran for thromboprophylaxis after joint-replacement surgery: exploratory indirect comparison based on meta-analysis of pivotal clinical trials. Croat Med J. 2010;51:113-123.

54. Harenberg J, Marx S, Dahl OE, et al. Interpretation of endpoints in a network meta-analysis of new oral anticoagulants following elective total hip or knee replacement surgery. Thromb Haemost. 2012;108:903-912.

55. Bacchus F, Schulman S. Clinical experience with the new oral anticoagulants for treatment of venous thromboembolism. Arterioscler Thromb Vasc Biol. 2015;35:513-519.

56. Hirschl M, Kundi M. New oral anticoagulants in the treatment of acute venous thromboembolism - a systematic review with indirect comparisons. Vasa. 2014;43:353-364.

57. Kang N, Sobieraj DM. Indirect treatment comparison of new oral anticoagulants for the treatment of acute venous thromboembolism. Thromb Res. 2014;133:1145-1151.

58. Mantha S, Ansell J. Indirect comparison of dabigatran, rivaroxaban, apixaban and edoxaban for the treatment of acute venous thromboembolism. J Thromb Thrombolysis. 2015;39:155-165.

59. Castellucci LA, Cameron C, Le Gal G, et al. Clinical and safety outcomes associated with treatment of acute venous thromboembolism a systematic review and meta-analysis. JAMA. 2014;312:1122-1135.

60. Sobieraj D, Coleman CI, Pasupuleti V, Deshapande A, Kaw R, Hernandez AV. Comparative efficacy and safety of anticoagulants and aspirin for extended treatment of venous thromboembolism: a network metaanalysis. Thromb Res. 2015;135:888-896.

61. Castellucci L, Cameron C, Le Gal G, et al. Efficacy and safety of oral anticoagulants and antiplatelet drugs in the secondary prevention of venous thromboembolism: systematic review and network metaanalysis. BMJ. 2013;347:f5133. 
62. Mahan CE. Practical aspects of treatment with target specific anticoagulants: initiation, payment and current market, transitions, and venous thromboembolism. J Thromb Thrombolysis. 2015;39:295-303.

63. Gómez-Outes A, Suárez-Gea ML, Lecumberri R, Terleira-Fernández AI, Vargas-Castrillón E. Direct acting oral anticoagulants: pharmacology, indications, management and future perspectives. Eur J Haematol. 2015;95:389-404.

64. Ward C, Conner G, Donnan G, Gallus A, McRae S. Practical management of patients on apixaban: a consensus guide. Thromb J. $2013 ; 11: 27$
65. Pollack CV Jr. Coagulation assessment with the new generation of oral anticoagulants. Emerg Med J. 2015;0:1-8.

66. Douxfils J, Mani H, Minet V, et al. Non-VKA oral anticoagulants: accurate measurement of plasma drug concentrations. Biomed Res Int. 2015;2015:345138.

67. Enriquez A, Lip GY, Baranchuk A. Anticoagulation reversal in the era of the non-vitamin K oral anticoagulants. Europace. Epub 2015 Mar 26.

Drug, Healthcare and Patient Safety

Dovepress

\section{Publish your work in this journal}

Drug, Healthcare and Patient Safety is an international, peer-reviewed open-access journal exploring patient safety issues in the healthcare continuum from diagnostic and screening interventions through to treatment, drug therapy and surgery. The journal is characterized by the rapid reporting of reviews, original research, clinical, epidemiological and post-marketing surveillance studies, risk management, health literacy and educational programs across all areas of healthcare delivery. The manuscript management system is completely online and includes a very quick and fair peer-review system. Visit http://www.dovepress.com/ testimonials.php to read real quotes from published authors.

Submit your manuscript here: http://www.dovepress.com/drug-healthcare-and-patient-safety-journal 